\title{
Relationship between Umbilical Cord C-peptide and Risk of Hypoglycemia in Infants of Diabetic Mothers
}

\author{
MST. NURUN NAHAR BEGUM ${ }^{1}$, M QUAMRUL HASSAN² ${ }^{2}$ KISHWAR AZAD ${ }^{3}$
}

\begin{abstract}
Objective: To examine the relationship between umbilical cord C-peptide and risk of hypoglycemia in infants of diabetic mothers.

Method: Sixty neonates born to diabetic mothers were studied in BIRDEM hospital. Thirty infants who developed hypoglycemia at any time during the first 24 hours of age were considered as cases. Another 30 infants who did not develop hypoglycemia during the first 24 hours were considered as controls. Umbilical cord C-peptide levels were measured in both groups. All babies were screened for hypoglycemia at 4, 6, 8, 12,18 and 24 hours of life. Blood glucose value of less than $2.6 \mathrm{mmol} / \mathrm{l}$ was considered as hypoglycemia.
\end{abstract}

\begin{abstract}
Results: Clinical characteristics of cases and controls and their mothers did not show any significant difference. In 73.3\% of cases hypoglycemia was detected by 6 hours of age. Most babies were asymptomatic (93.3\%). It was found that IDMs who developed hypoglycemia had significantly higher cord C-peptide level at birth compared to those who remained normoglycemic $(4.57 \pm 2.50 \mathrm{vs}$. $2.81 \pm 2.11 \mathrm{ng} / \mathrm{ml}, P=0.005)$. That means, there is significant association between raised level of cord C-peptide and hypoglycemia in IDMs.
\end{abstract}

Conclusion: Hypoglycemia in infants of diabetic mothers associated with raised cord blood C-peptide levels.

Introduction:

The prevalence of glucose intolerance in Bangladesh is $12.4 \%^{1}$. Diabetes is a fairly common medical complication of pregnancy associated with maternal, foetal and neonatal morbidities and mortalities. About $7 \%$ of all pregnancies are complicated by gestational diabetes mellitus (GDM) ${ }^{2}$ comparable to $6.8 \%$ in Bangladesh reported by Sayeed et $\mathrm{al}^{3}$. The duration and severity of maternal diabetes and quality of control during pregnancy determine the outcome of pregnancy in terms of maternal and fetal morbidities.

Among the various metabolic consequences these (IDM) suffer, hypoglycemia is the commonest and most serious because of its association with both acute

1. Assistant Professor, Neonatology, Sir Salimullah Medical College \& Mitford Hospital, Dhaka, e-mail- itsnahar@ yahoo.com

2. Senior Consultant, Paediatrics and Neonatology, Apollo Hospitals, Dhaka, e-mail-mquamrul@gmail.com

3. Project director, BADAS - Perinatal Care Project, \& Sr. Hony. Consultant, Dept. of Paediatrics, BIRDEM, e- mail: pcp@dabbd.org

Correspondence: Dr. Mst. Nurun Nahar Begum, e-mailitsnahar@yahoo.com decompensation and long-term neuronal loss. ${ }^{4}$ Most IDMs are prone to develop severe but asymptomatic hypoglycemia during the first postnatal hours ${ }^{5}$.

Hypoglycemia in IDMs is the result of maternal hyperglycemia in pregnancy and consequent foetal hyperglycemia and hyperinsulinemia. The normal plasma hormonal pattern of low insulin, low glucagon, and high catecholamines is reversed to a pattern of high insulin, low glucagon, and low epinephrine in IDMs. As a consequence of this abnormal hormone profile, endogenous glucose production is significantly inhibited compared with that in normal infants, thus predisposing them to hypoglycemia. ${ }^{6}$ As hyperinsulinemic hypoglycemia is a major risk factor for brain injury and subsequent neurodevelopmental handicap, the identification, rapid diagnosis and prompt management of patients with or without hypoglycemia is essential if brain damage is to be avoided ${ }^{7}$.

Human C-peptide is a 31 amino acid chain and is secreted from the beta cells of pancreas in equimolar ratio with insulin. Cord serum levels of C-peptide are used as an index of fetal beta-cell function, rather 
than insulin levels, because degradation of insulin is increased in the presence of slight hemolysis. ${ }^{8}$ In a previous study Kuhl et $\mathrm{al}^{9}$ reported that IDMs who became hypoglycemic at 2 hours of life had significantly higher levels of glucose and immunoreactive insulin in cord blood than IDMs who remained normoglycemic. Metzer $\mathrm{B} E$ et al ${ }^{10}$ also found that frequency of neonatal hypoglycemia was higher with higher cord C-peptide levels and newborns with hypoglycemia tended to have a higher frequency of cord C-peptide levels of more than $90^{\text {th }}$ percentile.

So umbilical cord C-peptide levels provide direct indication of endogenous fetal levels of insulin and could predict hypoglycemia in early neonatal life.

\section{Materials and methods:}

This case-control study was carried out in the department of Obstetrics and Gynecology, and Special Care Baby Unit (SCABU) at BIRDEM. (Bangladesh Institute of Research and Rehabilitation in Diabetes, Endocrine and Metabolic Disorders).

Sixty neonates born to diabetic mothers during November 2004 through February 2005 were studied. IDMs with major congenital malformation at birth, severe perinatal asphyxia and severe erythroblastosis foetalis were excluded from study. Neonates were screened for blood glucose at 4, 6, 8, 12, 18, 24 hours of postnatal age as per existing routine SCABU schedule irrespective of feeding status. Thirty infants who developed hypoglycemia at any time during the first 24 hours of age were considered as cases. Another 30 infants who did not develop hypoglycemia during the first 24 hours were considered as controls. Blood glucose value of $<2.6 \mathrm{mmol} / \mathrm{l}$ was considered as neonatal hypoglycemia ${ }^{4}$. Cord blood samples for estimation of C-peptide level were collected during delivery from baby side taking $2 \mathrm{ml}$ blood in plain test tube. The samples were centrifuged, and serum was separated and stored at $-20^{\circ} \mathrm{C}$ before assay by chemiluminescence ELISA using IMMULITE 2000, USA. Blood glucose level of IDMs was measured by Precision-plus (MediSense, USA) glucometer using glucose oxidase method at birth in cord blood, and thereafter at bed side blood sample obtained from heelprick. Results were analyzed by using Statistical Package for Social Science (SPSS Version 11.0) software package. Informed consent were taken from parents. It was clearly communicated that no additional blood sample would be collected, no extra procedures would be done and no modification of treatment plan would be made.
Results:

Table-I

Clinical characteristics of mothers and newborns

\begin{tabular}{lcc}
\hline Characteristics of mothers & Case & control \\
\hline Age (year) mean \pm SD & $29.47 \pm 4.81$ & $31.13 \pm 5.51$ \\
Weight $(\mathrm{kg})$ mean \pm SD & $61.17 \pm 10.17$ & $58.60 \pm 8.88$ \\
Type of Diabetes & $10(33.3 \%)$ & $11(36.7 \%)$ \\
$\quad$ GDM & $18(60 \%)$ & $19(63.3 \%)$ \\
Type 2 Diabetes & $2(6.7 \%)$ & 0 \\
$\quad$ Type 1 Diabetes & & $7(23.3 \%)$ \\
Treatment of Diabetes & $6(20 \%)$ & $23(76.7 \%)$ \\
Diet alone & $24(80 \%)$ & 0 \\
Diet and Insulin & & $30(100 \%)$ \\
Mode of delivery & $3(10 \%)$ & \\
NVD & $27(90 \%)$ &
\end{tabular}

Characteristics of newborn infants

\begin{tabular}{lcc} 
Birth weight $(\mathrm{gm})$ & $3065 \pm 725$ & $3252 \pm 464$ \\
mean \pm SD & & \\
Gestational age $(w k) \pm$ SD & $37 \pm 1.26$ & $37.2 \pm 0.71$ \\
Male & $14(46.6 \%)$ & $15(50 \%)$ \\
Female & $16(53.3 \%)$ & $15(50 \%)$ \\
Term & $19(63.3 \%)$ & $23(76.7 \%)$ \\
Preterm & $11(36.7 \%$ & $7(23.3 \%$ \\
AGA & $27(90 \%)$ & $28(93.3 \%)$ \\
LGA & $3(10 \%)$ & $2(6.67 \%)$ \\
\hline
\end{tabular}

LGA: large for gestational age AGA: appropriate for gestational age

Note : Difference between cases and controls by $\div 2$ test and Unpaired $\mathrm{t}$-test - Not significant

Table II

Distribution of cases by age (hour) at hypoglycemic episodes $(n=30)$

\begin{tabular}{lcc}
\hline $\begin{array}{l}\text { Age (hours) at } \\
\text { hypoglycemia }\end{array}$ & No. of cases & Percentage \\
\hline 4 hours & 15 & 50.0 \\
6 hours & 7 & 23.3 \\
8 hours & 4 & 13.3 \\
12 hours & 4 & 13.3 \\
\hline Total & 30 & 100 \\
\hline
\end{tabular}




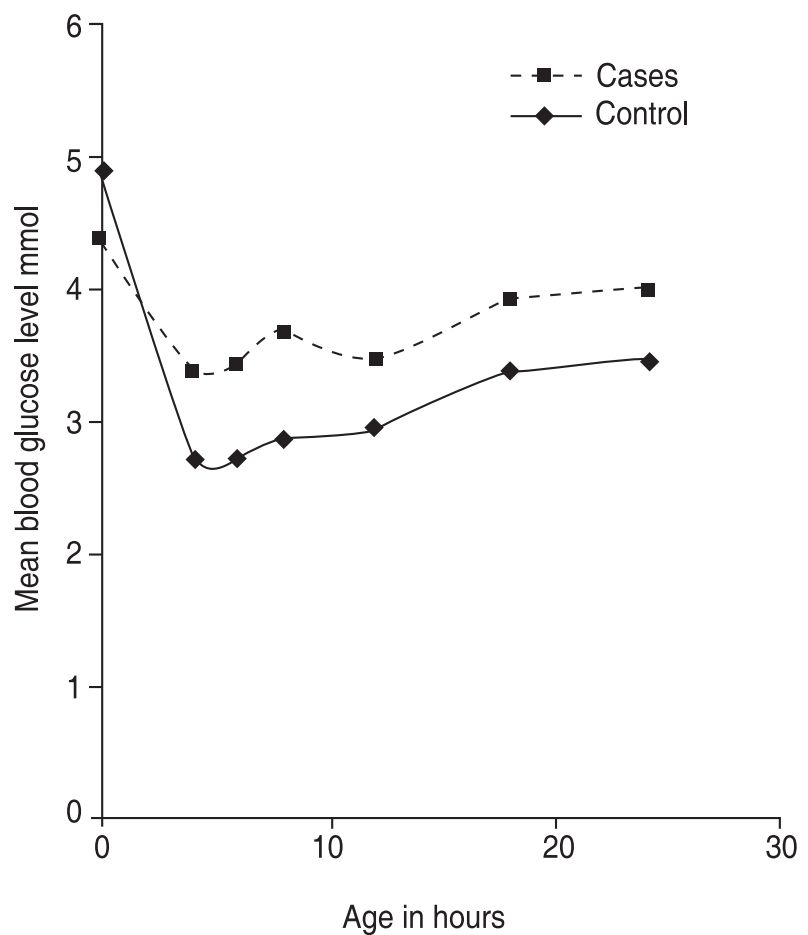

Fig.-1: Graph showing blood glucose status over 24 hours of postnatal age

Table-III

Comparison of cord blood C-peptide between cases and controls

\begin{tabular}{lccc}
\hline Subjects & Number & $\begin{array}{c}\text { C-peptide } \\
(\text { mean } \pm \text { SD }) \\
\text { in } \mathrm{ng} / \mathrm{ml}\end{array}$ & P value \\
\hline Cases & 30 & $4.57 \pm 2.50$ & 0.005 \\
Controls & 30 & $2.81 \pm 2.11$ & \\
\hline
\end{tabular}

Difference $[95 \% \mathrm{Cl}]: 1.76[0.56,2.96]$

Student's $t: 2.95$, DF : 58 p-value : 0.005

Table-I shows baseline characteristics of IDMs and their mothers in both groups. There is no significant difference in demographic features among cases and control. Hypoglycemia was detected in $50 \%$ of cases at 4 hours of age and in $23.3 \%$ at 6 hours of age. At 8 hours and also at 12 hours of life hypoglycemia was detected in $13.3 \%$ of cases.(Table II). Trend of blood glucose status of babies during first 24 hours of postnatal age is shown in fig-1. In both groups, blood glucose level decreased rapidly after birth, then from 4 hours onwards blood glucose level increased in both groups over next 24 hours of postnatal period, glucose level of cases were persistently remain in lower level than that of controls with significant difference of mean blood glucose values between cases and controls at $4 \mathrm{hr}(2.71$ vs $3.38 \mathrm{p}=0.003)$, at $6 \mathrm{hr}(2.71$ vs 3.45 $\mathrm{p}=0.0004)$, at $8 \mathrm{hr}(2.87$ vs $3.68 \mathrm{p}=0.0004)$, at $12 \mathrm{hr}$ 92.96 vs $3.47 p=0.008)$ and 24 ( 3.45 vs $4.0 p=0.006)$ of age. Majority of babies in cases $(66.7 \%)$ and $40 \%$ of controls had cord C-peptide values more than normal reference values of 0.8 to $3 \mathrm{ng} / \mathrm{ml}$. However mean umbilical cord serum C-peptide level in IDMs of cases (4.57) was significantly higher (P value 0.005 ) than that of control babies (2.81). (Table III)

\section{Discussion}

Neonatal hypoglycemia in association with hyperinsulinemia represents the crux of the Pedersen hypothesis and the concept has been validated repeatedly for the offspring of mothers with diabetes ${ }^{10}$.

Of the 60 studied IDMs, no significant difference was observed between clinical characteristics of cases and controls and their mothers. After birth plasma glucose fell in all infants, the nadir being reached in IDMs in first 1- 4 hours of life ${ }^{11}$ also reported in studies by Agrawal et al ${ }^{12}$ and Robert $S$ et al ${ }^{13}$. Clinically 2 hour levels are predictive of later hypoglycemia but may require repeat blood glucose (BG) testing. Audit is an important tool to validate national guidelines, to minimize their burden and to maximize their utility. ${ }^{14}$

Hypoglycemia was detected by 6 hours of age in majority of cases $(73.3 \%)$. Tanzer et al ${ }^{15}$ reported the lowest blood glucose values in healthy infants during first 3 hours, at 2 hours by Robert $\mathrm{S}$ et al ${ }^{13}$ given the emphasis that glucose monitoring in IDMs need only be done in first 2 hours of life, We did not examine the blood glucose at 2 hours and glucose level was done irrespective of feeding status, as we followed the existing SCABU protocol. Probably it would have been more frequent or severe if glucose estimation could have been done prefeed and also at 2 hours of life.

Maayan-Metzer et al ${ }^{16}$ studied pre-feed glucose values of 280 IDMs, where $48.6 \%$ developed mild to moderate hypoglycemia ( 2.2 to $2.5 \mathrm{mmol} / \mathrm{l}$ and 1.7 to $2.1 \mathrm{mmol} /$ I) and $4 \%$ severe hypoglycemia $(<1.7 \mathrm{mmol} / \mathrm{l})$. The normal adaptation of this physiological hypoglycemia also demands early feeding to prevent severe hypoglycemia. Of the 30 hypoglycemic babies majority $(93.3 \%)$ were asymptomatic. The predominance of asymptomatic hypoglycemia in our study consistent with previously reported studies ${ }^{12,13}$ 
However, the absence of overt symptoms at low blood glucose levels does not rule out central nervous system injury ${ }^{17}$. Neonatal hypoglycemia is associated with poor psychoneurological outcome. Evidence suggests that blood glucose should be maintained above 2.6 $\mathrm{mmol} / \mathrm{l}$ to ensure normal neural function in infants irrespective of the presence or absence of abnormal clinical signs ${ }^{18}$.

Babies born to diabetic mothers are hyperinsulinemic and the neonatal hypoglycemia seems to result from this together with a delay in increasing plasma glucagon levels ${ }^{5}$. C-peptide which provides an indication of insulin secretion is directly related to the severity of maternal diabetes, significantly associated with neonatal complications including hypoglycemia ${ }^{10,19}$

In the present study C-peptide values in majority of cases $(66.7 \%)$, whereas $40 \%$ of controls were above normal values indicates raised level even in strict metabolic control done in this specialized centre during pregnancy.

The mean value of cord blood C-peptide in IDMs who became hypoglycemic is $(4.57 \pm 2.5)$ higher than in IDMs who remained normoglycemic (2.81 \pm 2.1$)$ which is statistically significant $(P=0.005)$. Similar finding also reported by Abdelgadir et $\mathrm{al}^{20}$, Goudard et $\mathrm{al}^{21}$, Fallucca $\mathrm{F}$ et al ${ }^{22}$. This significant difference of mean C-peptide value means that there may be an association between high $\mathrm{C}$-peptide and risk of hypoglycemia in IDMs.

IDMs are markedly hyperinsulinemic at birth and that ambient hyperinsulinemia plays a crucial role in the development of foetal macrosomia and neonatal hypoglycemia ${ }^{23}$. Metzer $\mathrm{BE}$ et ${ }^{10}$ al in his study reported that biochemical and clinical hypoglycemia were strongly associated with elevated cord serum C-peptide levels but weakly related to maternal OGTT glucose measurements.

We have also examined the relationship of blood glucose values of all IDMs with cord C-peptide levels which showed significant inverse relation ( $r$ value $0.326 p$ value .011 ). This finding is comparable with others studies that reported cord C-peptide levels were found to be inversely related to blood glucose concentration in early postnatal period $10,21,22$. But Mohajeri Tehrani et $\mathrm{al}^{24}$ and Stenninger $\mathrm{E}$ et $\mathrm{al}^{25}$ found association between cord C-peptide and macrosomia in IDMs but not with hypoglycemia.

The significant correlation of increased cord blood insulin with neonatal hypoglycemia in IDMs being observed by Dawid $\mathrm{G}$ et $\mathrm{al}^{26}$ and Knip et al ${ }^{23}$. As Cpeptide secreted in equimolar concentration with insulin, so this high insulin levels also represent the high C-peptide at the same time. Similar observation has also been reported by Cooper et $\mathrm{al}^{27}$. So there is significant association of high cord C-peptide and postnatal hypoglycemia.

\section{Conclusion:}

Raised level of cord blood C-peptide is significantly associated with early postnatal hypoglycemia in babies born to diabetic mothers.

\section{Recommendation:}

Neonatal hypoglycemia has been linked to poor neurodevelopmental outcome. Increased prevalence of asymptomatic neonatal hypoglycemia in IDMs stress the importance of systematic glucose monitoring at risk babies to prevent severe and recurrent hypoglycemia.

\section{Limitation of the study}

Sample size is small, needs further study with a larger sample size, specially size of control which should be at least 1.5 times of cases.

C-peptide is not a routine test, fairly costly.

\section{References}

1. Rahim M.A, Khan A K A, Ali S.M.K, Nahar Q, Shaheen A, Hussain A. Glucose tolerance in a rural population of Bangladesh. Int J Diabetes Dev Ctries 2008; 28(2): 45-50.

2. Diagnosis and classification of diabetes mellitus. American Diabetes association. Diabetes care 2010; 33 suppl: S62-69.

3. Sayeed MA, Mahtab H, Khanam PA, Begum R, Banu A, Azad Khan AK. Diabetes and Hypertension in pregnancy in a rural community of Bangladesh: a population based study. Diabet Med. 2005; 22(9): 1267-1271.

4. Lucas, A and Morley, R and Cole, TJ (1988) Adverse neurodevelopmental outcome of moderate neonatal hypoglycaemia. BMJ (Clinical Research Ed.) 1988; 297 (6659): 1304 - 1308.

5. Hertel J, Kuhl C. Metabolic adaptation during the neonatal period in infants of diabetic mothers. Acta Endocrinol Suppl (Copenh) 1986; 277: $136-40$

6. Sperling M A. Hypoglycemia. In: Kleigman, Behrman, Jenson, Stanton eds. Nelson Textbook of Pediatrics. $1^{\text {th }}$ edition. Philadelphia, Saunders, Elsevier 2008: 659

7. Kapoor R R, Flanagan SE, James C, Shield J, Ellard E, Hussain K. Hyperinsulinaemic hypoglycemia. Arch Dis Child 2009; 94:450-457 
8. O'Rahilly S, Burnett MA, Smith RF, Darley JH, Turner RC. Haemolysis affects insulin but not C-peptide immunoassay. Diabetologia. 1987; 30(6):394-396.

9. Kuhl C, Andersen GE, Hertel J, MolstedPedersen L. Metabolic events in infants of diabetic mothers during the first 24 hours after birth. I. Changes in plasma glucose, insulin and glucagon. Acta Paediatr Scand 1982; 71: 1925.

10. Metzer BE. Hyperglycemia and adverse pregnancy outcome study: neonatal glycemia. Pediatrics.2010 Dec; 126(6):e1545-52. Epub 2010 Nov 15.

11. Hawdon, J.M. Aynsley-Green, A, The infant of diabetic mother. In: N.R.C. Roberton, Janet M. Rennie, eds. Textbook of Neonatology. $3^{\text {rd }}$ edition. Edinburgh : Churchill Livingstone: 1999. 401-07.

12. Agrawal, R.K. Lui, K. Gupta, J.M. Neonatal hypoglycemia in infants of diabetic mothers. J Paediatr Child Health 2000; 36(4): 354-56.

13. Robert S, Van Howe, Michelle R, Storms. Hypoglycemia in Infants of Diabetic Mothers: experience in a Rural Hospital. Amer J Perinatol 2006; 23(2): 105-110.

14. Jennifer Croke BSc, Meagan Sullivan BSc, Anne Ryan-Drover FRCPC, Ed Randell PhD, Wayne Andrews FRCPC, Khalid Aziz FRCPC FRCPCH. Two hour blood glucose levels in at risk babies: An audit of Canadian guidelines. Paediatr child Health 2009; 14(4): 238-244.

15. Tanzer F, Yazar N, Yazar H, Icagasioglu D. Blood glucose levels and hypoglycemia in full term neonates during the first 48 hours of life. J Trop Pediatr. 1997; 43(1):58-60.

16. Maayan-Metzer A, Lubin D, Kuint J. Hypoglycemia rates in the first days of life among term infants born to diabetic mothers. Neonatology. 2009; 96(2):80-5. Epup 2009 Feb 19.

17. Richard E. Wilker. Hypoglycemia and Hyperglycemia. In: Cloherty JP, Eichenwald EC, StarkAR,editors. Mannual of Neonatal Care. $6^{\text {th }}$ Edition ed:Lippincott Williams Wilkins. Philadelpia:2008: 541

18. Koh TH, Aynsley-Green A, Tarbit M, Eyre JA. Neural dysfunction during hypoglycaemia. . Archives of disease in childhood 1988; 63: $1353-58$.
19. Sosenko, I.R. Kitzmiller, J.L. Blix, P. Rubenstein, A.H. Gabbay, K.H. The infant of diabetic mother : correlation of increased cord C-peptide levels with macrosomia and hypoglycemia. N Engl J Med 1979; 301 (16): 859-62.

20. Abdelgadir, M. Elbagir, M. Eltom, A. Eltom, M. Berne, C. Factors affecting perinatal morbidity and mortality in pregnancies complicated by diabetes mellitus in Sudan. Diabetes Research and Clinical Practice 2003; 60: 41-47.

21. Gouedard HA, Menez JE, Meskar A, Caroff J, Lucas D, Legendre JM. Perinatal assessment of glycemic control in newborn infants of diabetic mothers. Diabetologia 1984 Dec; 27(6):553-7

22. Fallucca F, Maldonato A, lavicoli M, Di Rollo G, Di Biase N, Napoli A, de Vecchis P, Sciullo E, Gerlini G, Pachi A. Influence of maternal metabolic control and insulin antibodies on neonatal complications and $B$ cell function in infants of diabetic mothers. Diabetes Res clin Pract. 1989 Nov 6; 7(4): 277-84.

23. Knip M, Lautala P, Leppaluoto J, Akerblom HK, Kouvalainen K. Relation of enteroinsular hormones at birth to macrosomia and neonatal hypoglycemia in infants of diabetic mothers. $J$ Pediatr 1983; 103(4): 603-11

24. Mohjeri Tehrani, Amini Moghaddam, Annabestani, Hesmat, Alyasin, Aghaie Meibodi, Bagher Larjani, Amniotic fluid, maternal and neonatal serum C-peptide as predictor of macrosomia; A pilot study. Iranian Journal of Diabetes and Lipid Disorders 2009; 8: 15

25. Stenninger E, Schollin J, Aman J. Neonatal Macrosomia and Hypoglycemia in Children of Mothers with Insulin-Treated Gestational Diabetes Mellitus. Acta Paediatrica 1991; 80 (11): 1014-1018.

26. Dawid g, Horodnicka-Jozwa A, Petriczko E, Biczysko-Mokosa A. Diabetes in pregnancy: cord blood insulin level and neonatal outcome in relation to maternal glycated haemoglobin A1c in last trimester of pregnancy. Pediatr Endocrinol diabetes Metab 2009;15(4):253-9

27. Cooper M.J, Enderlein M.A, Tarnoff H, Roge C. L. Asymmetrical septal hypertrophy in infants of diabetic mothers. Fetal echocardiography and impact of maternal control. Am J Dis Child 1992; 146(2): 226-9. 